\title{
THE EFFECT OF NITRIC OXIDE SYNTHASE INHIBITOR ON REPERFUSION INJURY OF THE BRAIN UNDER HYPOTHERMIC CIRCULATORY ARREST
}

Daisuke Segawa, MD

Nobuo Hatori, MD, PhD

Hiroshi Yoshizu, MD

Yozo Uriuda, MD

Masafumi Shimizu, MD

Susumu Tanaka, MD
Objective: The objective of this study was to investigate the protective effects of nitric oxide synthase inhibitor, $N^{\mathrm{G}}$-nitro-L-arginine methyl ester hydrochloride, on reperfusion injury of the brain under hypothermic circulatory arrest. Methods: After cardiopulmonary bypass was established using 12 piglets each weighing about $30 \mathrm{~kg}$, the animals were cooled to a brain temperature of $20^{\circ} \mathrm{C}$ and circulatory arrest was performed for 90 minutes followed by reperfusion for 120 minutes. The level of nitric oxide within the brain was measured with a needle electrode inserted into the brain. In the treatment group, $N^{\mathrm{G}}$-nitro-L-arginine methyl ester hydrochloride was administered with an intravenous injection of $1.5 \mathrm{mg} / \mathrm{kg}$ at the onset of the reperfusion followed by a 60 -minute continuous venous infusion of 1.5 $\mathrm{mg} / \mathrm{kg} / \mathrm{hr}$. Results: In the control group, nitric oxide levels within the brain increased not during ischemia but during reperfusion, and the level after 120 minutes of reperfusion increased significantly compared with that of before circulatory arrest. But in the treatment group, $N^{\mathrm{G}}$-nitro-L-arginine methyl ester hydrochloride administered at the onset of reperfusion inhibited nitric oxide production during reperfusion. A significant difference was observed between the groups regarding the nitric oxide level after 120 minutes of reperfusion. Regarding cerebral blood flow, excess lactate, and cerebral tissue water content, no significant difference was observed between the groups. However, recovery of somatosensory evoked potential after 120 minutes of reperfusion was detected in all six animals in the treatment group, but none in the control group $(p=0.001)$. Conclusion: These data suggest that $N^{\mathrm{G}}$-nitro-L-arginine methyl ester hydrochloride protects the brain against reperfusion injury under hypothermic circulatory arrest. (J Thorac Cardiovasc Surg 1998;115:925-30)
D uring operation of the aortic arch, a risk of cerebral damage, resulting from restriction of cerebral blood supply, is present. Therefore various techniques for cerebral protection during ischemia, for example hypothermic circulatory arrest, selective cerebral perfusion, and retrograde cerebral perfusion, are used. Hypothermic circulatory arrest is easy to perform but it is not suitable for longer

From the Department of Surgery II, National Defense Medical College, Saitama, Japan.

Received for publication March 20, 1997; revisions requested Sept. 15, 1997; revisions received Oct. 8, 1997; accepted for publication Oct. 9, 1997.

Address for reprints: Daisuke Segawa, MD, Department of Surgery II, National Defense Medical College, 3-2 Namiki, Tokorozawa, Saitama 359, Japan.

Copyright (C) 1998 by Mosby, Inc.

$0022-5223 / 98 \$ 5.00+0 \quad \mathbf{1 2 / 1 / 8 6 8 8 3}$ operations. The other techniques are more complicated and difficult to perform.

During normothermic cerebral ischemia, nitric oxide (NO) within the brain is overproduced, and the overproduced NO is thought to be neurotoxic. ${ }^{1}$ However, the role of NO during reperfusion after hypothermic circulatory arrest has not been investigated.

The aim of this study was to measure the levels of NO within the brain during ischemia with hypothermic circulatory arrest and reperfusion using cardiopulmonary bypass (CPB) and furthermore to investigate the effect of an NO synthase inhibitor (NOSI) on the cerebral reperfusion injury.

\section{Materials and methods}

Experimental preparations. Twelve farm piglets of either sex, weighing 31 to $35 \mathrm{~kg}$, were premedicated with an intramuscular injection of $20 \mathrm{mg} / \mathrm{kg}$ ketamine hydrochlo- 
ride and $1.0 \mathrm{mg} / \mathrm{kg}$ body weight atropine sulfate. Anesthesia was induced with an intravenous injection of $20 \mathrm{mg} / \mathrm{kg}$ sodium pentobarbital and maintained with a continuous intravenous infusion of sodium pentobarbital, $10 \mathrm{mg} / \mathrm{kg} /$ $\mathrm{hr}$, and an intermittent intravenous injection of $1 \mathrm{mg} / \mathrm{kg}$ body weight/hr pancuronium bromide. The tracheas of the piglets were intubated and the piglets' lungs were mechanically ventilated with a respirator with room air. Respiratory rate and tidal volume were adjusted to keep arterial $\mathrm{pH}$ between 7.35 and 7.45 and carbon dioxide tension $\left(\mathrm{PcO}_{2}\right)$ between 35 and $45 \mathrm{~mm} \mathrm{Hg}$. A $7 \mathrm{~F}$ catheter was inserted into the left femoral vein for administration of fluids, and another $7 \mathrm{~F}$ catheter was inserted into the external jugular vein for withdrawal of venous blood specimens from the brain circulation. A $6 \mathrm{~F}$ catheter inserted into the left femoral artery was connected to a transducer (RM-6000, Nihon Koden, Saitama, Japan) for measurement of blood pressure and was used for withdrawal of arterial blood specimens.

Craniotomy was performed and a needle electrode, 0.2 $\mathrm{mm}$ in diameter (NOE-55, Intermedical Inc., Tokyo, Japan), for measurement of NO within the brain was inserted into the cortex of the right temporal lobe through the dura mater. The electrode was connected with a NO monitor (model NO-501, Intermedical Inc., Tokyo, Japan). This monitor expressed NO levels continuously as pico-amperes. $^{2}$ In the same way, a needle electrode (HGE-10N, Intermedical Inc., Tokyo, Japan) for measurement of regional cerebral blood flow was inserted near the NO needle electrode and connected with a hydrogen clearance-type monitor (model-HG-200, Intermedical Inc., Tokyo, Japan). To obtain a somatosensory evoked potential (SEP) by stimulating the left radial nerve, working and counter electrodes of an electroencephalograph were put on the surfaces of the right temporary lobe and the frontal lobe, respectively, and connected to a recorder (MEB-5200, Nihon Koden, Saitama, Japan). To monitor the temperature of the brain, a microprobe connected to a thermometer (model TH-6, Bailey, N.J.) was put between the cranial bone and dura mater in the occipital region.

Through a right pararectus incision the right external iliac artery was extraperitoneally exposed. Right thoracotomy was performed in the fourth intercostal space, and the pericardium was opened. After administration of heparin, $300 \mathrm{IU} / \mathrm{kg}$, a $16 \mathrm{~F}$ perfusion cannula was inserted into the iliac artery and $30 \mathrm{~F}$ and $32 \mathrm{~F}$ drainage cannulas were inserted through the right atrium into the superior and inferior caval veins, respectively, and CPB was established.

The experimental protocol and animal care was approved by the local ethics committee for animal research, which conforms to the "Guide for the Care and Use of Laboratory Animals," published by U.S. National Institutes of Health (NIH publication No. 85-23, revised 1985).

Experimental protocol. The CPB circuit was primed with Ringer's lactate to achieve a hematocrit value of $20 \%$ to $25 \%$ and a flow rate of CPB was maintained at 50 $\mathrm{ml} / \mathrm{kg} / \mathrm{min}$. The arterial $\mathrm{Pco}_{2}$ was kept at 35 to $45 \mathrm{~mm} \mathrm{Hg}$ and oxygen tension $\left(\mathrm{Po}_{2}\right)$ at 450 to $500 \mathrm{~mm} \mathrm{Hg}$. To keep arterial $\mathrm{pH}$ between 7.35 and 7.45 during $\mathrm{CPB}$, the proper dose of sodium bicarbonate was occasionally infused according to blood base excess. Animals were cooled to a brain temperature of $20^{\circ} \mathrm{C}$ and circulatory arrest was performed for 90 minutes followed by reperfusion for 120 minutes. NO levels within the brain were measured throughout this period from pre-CPB to the end of reperfusion. In the treatment group, an NOSI, $N^{\mathrm{G}}$-nitroL-arginine methyl ester hydrochloride (L-NAME), was administered with an intravenous injection of $1.5 \mathrm{mg} / \mathrm{kg}$ at the onset of reperfusion, followed by a 60 -minute continuous venous infusion of $1.5 \mathrm{mg} / \mathrm{kg} / \mathrm{hr}$. In the control group the same volume of saline solution was administered.

Body and brain temperatures, NO levels, and SEP were measured before $\mathrm{CPB}$, at the beginning of $\mathrm{CPB}$, before circulatory arrest, after 90 minutes of circulatory arrest, and after 60 and 120 minutes of reperfusion. Blood pressure and regional cerebral blood flow were measured before $\mathrm{CPB}$, at the beginning of $\mathrm{CPB}$, before circulatory arrest, at the beginning of reperfusion, and after 60 and 120 minutes of reperfusion.

Postmortem study. At the end of the study the animals were killed by cessation of CPB and the brains were excised immediately. Cerebral tissue water content was calculated as the following formula with wet and dry weights of the brain. The dry weight was obtained after desiccation at $80^{\circ} \mathrm{C}$ for 48 hours. Cerebral tissue water content $(\%)=($ Wet weight - Dry weight $) /$ Wet weight $\times$ 100.

Plasma study. Five milliliters of arterial specimens from the left femoral artery and $2 \mathrm{ml}$ of venous specimens from the right external jugular vein were drawn before $\mathrm{CPB}$, just before circulatory arrest, just after circulatory arrest, and after 120 minutes of reperfusion. Two milliliters of the arterial specimens and venous specimens were mixed with trichloroacetic-hydrochloric acid and centrifuged immediately for analysis of lactate and pyruvate. The remaining arterial specimens were collected in heparinized tubes and centrifuged immediately for analysis of aspartate aminotransferase (AST) and lactic dehydrogenase (LD). All plasma samples were removed and kept at $-80^{\circ} \mathrm{C}$ until analysis.

Lactate and pyruvate concentration were measured by lactate or pyruvate oxidase method, AST by ultraviolet method, and LD by Wroblewski-LaDue method. Excess lactate was calculated from lactate and pyruvate concentration in the artery and vein with Huckabeels method. ${ }^{3}$

To eliminate the effects of dilution for CPB, these obtained data were corrected as follows with the level of hematocrit. Corrected level $=$ Hematocrit at pre-CPB/ hematocrit at measurement $\times$ measured level.

Randomization procedure. Randomization was performed with a randomization code. The study was planned to include at least six successfully studied animals in each group. The investigators responsible for the surgical procedure were not informed of treatment allocation. All measurements, including NO levels, were also performed blindly.

Data analysis. Statistical analysis was performed with nonparametric tests because the data obtained in this study were not expected to be normal distributions. MannWhitney rank-sum test was used for comparison between the two groups. Comparisons within the group were performed by Friedman test and, if significant, further 
Table I. Comparison of control and treatment groups

\begin{tabular}{llcccc}
\hline & & Pre-CPB & Pre-CA & Post-CA & Reperfusion 120 min \\
\hline Body temperature $\left({ }^{\circ} \mathrm{C}\right)$ & Control & $37.1 \pm 0.6$ & $29.0 \pm 3.2^{*}$ & $25.5 \pm 1.5^{*}$ & $33.7 \pm 3.6$ \\
Brain temperature $\left({ }^{\circ} \mathrm{C}\right)$ & Treatment & $37.8 \pm 1.4$ & $26.2 \pm 2.5^{*}$ & $24.5 \pm 1.6^{*}$ & $33.0 \pm 1.0$ \\
& Control & $35.6 \pm 0.9$ & $20.8 \pm 0.7^{*}$ & $20.0 \pm 0.5^{*}$ & $35.7 \pm 0.7$ \\
Blood pressure $(\mathrm{mm} \mathrm{Hg})$ & Treatment & $35.8 \pm 1.1$ & $21.3 \pm 0.7^{*}$ & $19.8 \pm 0.4^{*}$ & $35.5 \pm 0.9$ \\
& Control & $126 \pm 15$ & $65 \pm 8^{*}$ & $62 \pm 9^{*}$ & $65 \pm 12^{*}$ \\
Cerebral blood flow (ml/min/100 gm) & Treatment & $133 \pm 19$ & $59 \pm 12^{*}$ & $55 \pm 12^{*}$ & $101 \pm 39$ \\
& Control & $18.5 \pm 7.8$ & $15.0 \pm 4.3$ & $19.2 \pm 6.9$ & $22.1 \pm 1.9$ \\
AST (IU/L) & Treatment & $18.3 \pm 4.9$ & $15.9 \pm 2.8$ & $17.8 \pm 1.8$ & $23.1 \pm 4.0$ \\
& Control & $36 \pm 9$ & $68 \pm 28$ & $88 \pm 75$ & $206 \pm 149^{*}$ \\
LD (IU/L) & Treatment & $36 \pm 12$ & $53 \pm 8$ & $78 \pm 48$ & $190 \pm 83^{*}$ \\
& Control & $1140 \pm 226$ & $1259 \pm 423$ & $1336 \pm 543$ & $2124 \pm 1214^{*}$ \\
Excess lactate $(\mathrm{mmol} / \mathrm{L})$ & Treatment & $1145 \pm 164$ & $1393 \pm 573$ & $1433 \pm 483$ & $1960 \pm 820^{*}$ \\
& Control & $0.09 \pm 0.22$ & $-2.89 \pm 4.38$ & $-3.61 \pm 5.27$ & $-14.84 \pm 14.52$ \\
& Treatment & $0.10 \pm 0.25$ & $-1.39 \pm 1.58$ & $-5.94 \pm 2.88$ & $-17.36 \pm 15.21$
\end{tabular}

$A S T$, Aspartate aminotransferase; $L D$, lactic dehydrogenase; $C P B$, cardiopulmonary bypass; $C A$, circulatory arrest.

*Significant difference compared with pre-CPB with $p$ value $<0.05$ with $95 \%$ confidence interval.

analysis was made with the Student-Newman-Keuls test for all possible pairwise comparisons. All data are presented as mean \pm standard deviation.

\section{Results}

Changes of body and brain temperatures. The average body weight of piglets in the control and the treatment groups was $32.2 \pm 1.5$ and $33.3 \pm 1.9 \mathrm{~kg}$, respectively. Cooling periods to a brain temperature of $20^{\circ} \mathrm{C}$ were $37.0 \pm 3.9$ and $37.2 \pm 4.2$ minutes, respectively. No significant difference was observed between the groups regarding body weight and cooling period. Body and brain temperatures are shown in Table I. The two groups were similar throughout the experiment regarding body and brain temperatures and no significant difference was observed between the groups.

Blood pressure and regional cerebral blood flow. Blood pressure and regional cerebral blood flow are shown in Table I. In the control group blood pressure decreased from $126 \pm 15 \mathrm{~mm} \mathrm{Hg}$ to $64 \pm 12$ $\mathrm{mm} \mathrm{Hg}$ on starting CPB and after that it hardly changed throughout the course, even during reperfusion. In the treatment group blood pressure decreased from $133 \pm 19 \mathrm{~mm} \mathrm{Hg}$ to $76 \pm 12 \mathrm{~mm} \mathrm{Hg}$ on starting $\mathrm{CPB}$ and until reperfusion it did not change remarkably. However, blood pressure increased gradually after reperfusion started and reached $85 \pm 31 \mathrm{~mm} \mathrm{Hg}$ after 60 minutes of reperfusion and $101 \pm 39$ after 120 minutes. However, this increase of blood pressure in the treatment group remained within the physiologic range. On the other hand, no significant difference was observed between the groups regarding cerebral blood flow at any phase, even after 120 minutes of reperfusion.

AST and LD of plasma, and excess lactate. AST and LD of plasma and calculated excess lactate are shown in Table I. Both AST and LD gradually increased in the course of the experiment. The two groups were comparable and no significant difference was observed between the groups. Excess lactate levels decreased during the course of the experiment in both the groups. No significant difference was observed between the groups in the levels of cerebral excess lactate at any phase.

Changes of NO levels within the brain. NO levels within the brain before CPB in the control and the treatment groups were $3744 \pm 2665$ and $3157 \pm$ $1806 \mathrm{pA}$, respectively. The levels at the beginning of $\mathrm{CPB}$ were $3358 \pm 2412$ and $3005 \pm 1848 \mathrm{pA}$. Because no significant difference was observed between the groups regarding these levels, the levels at pre-CPB, precirculatory arrest, after 90 minutes of circulatory arrest, and after 60 and 120 minutes of reperfusion were described as a percentage of the level at the beginning of CPB (Fig. 1). In both groups NO levels decreased in proportion to decrease of brain temperature during the cooling period. And during circulatory arrest NO levels slightly increased but not significantly compared with the level at the end of cooling period. After reperfusion started, NO levels increased further in the control group, and the increases were statistically significant. In the treatment NO levels increased further during the first hour after reperfusion started, but during the next hour NO levels gradually decreased. Compared with the level at the 


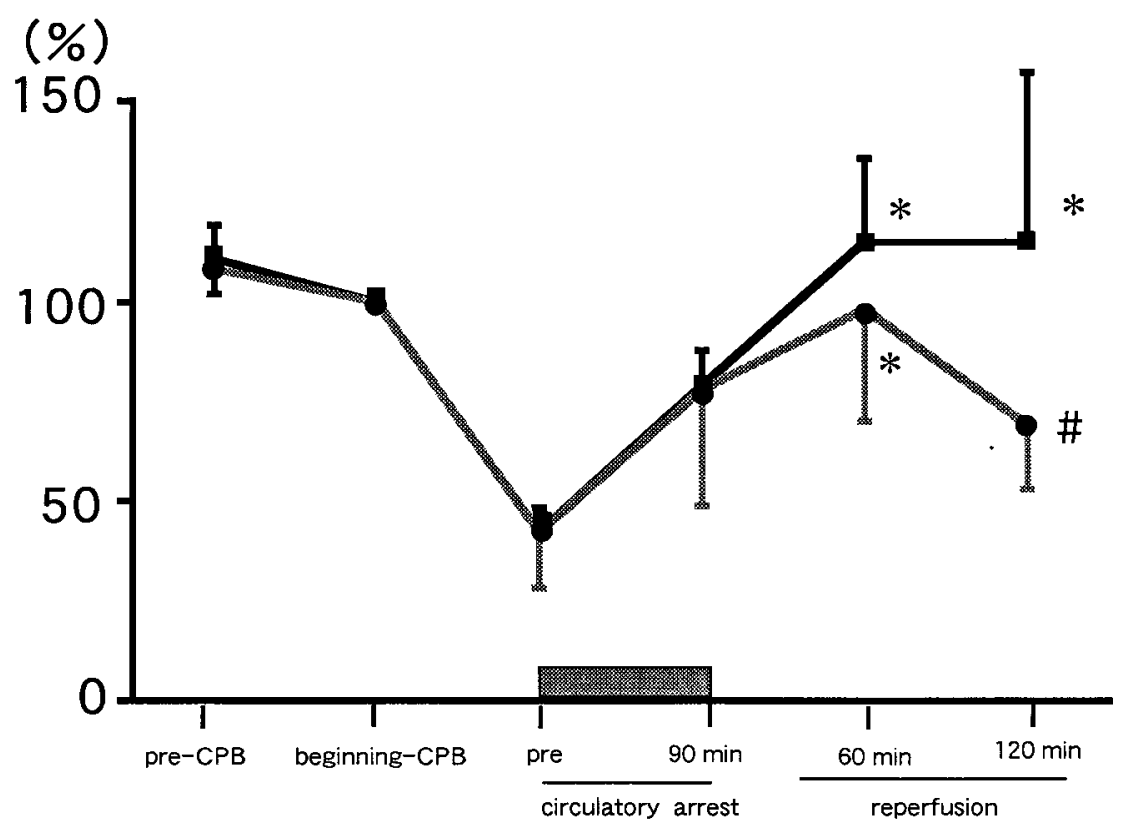

Fig. 1. Changes of nitric oxide levels within the brain. $\mathbf{0}$, control group; $\mathbf{0}$, treatment group. In the treatment group the levels of nitric oxide did not increase during the second 60 minutes after circulatory arrest and a significant difference was observed between the groups regarding nitric oxide level after 120 minutes of reperfusion. The shaded rectangle shows the circulatory arrest. $C P B$, Cardiopulmonary bypass; \#significant difference between the groups with $p$ value 0.004 ; * significant difference with $p$ value $<0.05$ compared with the value of precirculatory arrest with $95 \%$ confidence interval.

end of cooling period the increase after 60 minutes of reperfusion was statistically significant, but not after 120 minutes of reperfusion. A significant difference was observed between the groups regarding NO level after 120 minutes of reperfusion ( $p=$ 0.004).

Cerebral tissue water content. Cerebral tissue water contents were $82.4 \% \pm 0.2 \%$ in the control group and $82.0 \% \pm 0.5 \%$ in the treatment group. No significant difference was found between the groups. This meant that the extent of brain edema in both groups was comparable.

SEP. As brain temperature fell, electroencephalographic activity diminished and disappeared by $20^{\circ} \mathrm{C}$. In all cases the electroencephalogram remained flat during circulatory arrest. SEP was taken at 60 minutes after reperfusion started, but none in both groups showed recovery of SEP. After 120 minutes of reperfusion, SEP was detected in all the cases in the treatment group but none in the control group. This difference was significant $(p=0.001)$.

\section{Discussion}

Several former studies reported that NO concentration within the brain increased during normo- thermic ischemia and reperfusion. ${ }^{1-4}$ This study demonstrated the changes in NO levels within the brain during hypothermic circulatory arrest and reperfusion with cardiopulmonary bypass.

In this study, after CPB started, NO levels within the brain decreased in proportion to brain temperature decrease during the cooling period. NO levels increased slightly during ischemia at a brain temperature of $20^{\circ} \mathrm{C}$ and increased remarkably during reperfusion. It was thought that this increase of NO during reperfusion was one cause of reperfusion injury of the brain and that inhibition of this increase might lead to protection of the brain against reperfusion injury.

Some NOSIs are used in many experiments. Among them we chose L-NAME because it is reported that L-NAME inhibits NO production particularly and is suitable for cerebral experiments. ${ }^{5}$

NOSIs such as L-NAME are reported to reduce infarct size resulting from transient occlusion of the middle cerebral artery of rats and mice. ${ }^{6}$ Because NO works as a vasodilator, inhibition of NO production may induce vasoconstriction and a subsequent increase in blood pressure. Ashwal and colleagues $^{8}$ demonstrated that even a low dose of 
L-NAME, which did not cause an increase in blood pressure, had the same protective effect. They proved that this effect did not result from an increase in blood pressure. In our study L-NAME caused an increase in blood pressure but no significant change in regional cerebral blood flow, therefore the protective effect of L-NAME was not due to an increase in cerebral blood flow. On the other hand, some studies reported that NO was neuroprotective ${ }^{9}$ or NOSI harmed cerebral tissue ${ }^{10}$ during and after ischemia. Tsui and colleagues ${ }^{11}$ reported L-NAME $(50 \mathrm{mg} / \mathrm{kg})$ aggravated cerebral blood flow and oxygen metabolism, whereas L-arginine $(30 \mathrm{mg} /$ $\mathrm{kg}$ ) improved recovery after deep hypothermic circulatory arrest using little piglets. Hiramatsu and colleagues $^{12}$ reported in their study with piglets weighing about $4 \mathrm{~kg}$ that L-NAME administered before $\mathrm{CPB}$ had a deleterious effect on cerebral metabolic recovery. However, the dosage of L-NAME in these studies differed considerably from that in our study. Anderson and colleagues ${ }^{13}$ reported only low-dose $(<1 \mathrm{mg} / \mathrm{kg})$ L-NAME attenuated brain acidosis, and high-dose L-NAME had contradictory effects during repetitive focal cerebral ischemia. Other things, such as time for administration and condition of $\mathrm{CPB}$, also differed and NO levels were not measured. Moreover, the vulnerability of the developing central nervous system to hypoxia-ischemia is reported to differ from that of the mature brain. ${ }^{14}$ Therefore it is difficult to compare our study with theirs.

These two apparently contradictory opinions, that $\mathrm{NO}$ is neurotoxic or neuroprotective, are in fact compatible. One of the reasons is that NO could take two different forms with quite different actions, a radical form and an ionized form, depending on surrounding conditions. ${ }^{15}$ Although it is reported that the NO ion protects the cerebral tissue by inhibiting the function of $N$-methyl-D-aspartate receptor against glutamate-mediated neurotoxicity, NO radicals react with active oxygen and produce peroxynitrite, which harms the cerebral tissue. ${ }^{16}$

7-Nitroindazole, which inhibited only neuronal NO synthase, was reported to decrease cerebral infarct size caused by middle cerebral artery occlusion. ${ }^{17}$ Moreover, it was reported that ischemic injury was reduced in mice that were inherently deficient in neuronal NO synthase. ${ }^{18}$ Therefore overabundant NO synthesized by neurons is thought to be an aggravating factor of ischemic injury.

However, by maintaining blood flow the neuroprotective effects of $\mathrm{NO}$ are expected because NO essentially has a vasodilatative action and inhibits platelet aggregation. Moreover, NO inhibits leukocyte emigration and adherence to vascular endothelium. ${ }^{19}$ Therefore it is expected that NO reduces the no reflow phenomenon during reperfusion and neurotoxicity of the superoxide anion deriving from leukocytes. It is reported that excess NO synthesized by neurons may be neurotoxic and $\mathrm{NO}$ deriving from endothelium may be neuroprotective. ${ }^{14}$ According to our study, recovery of SEP indicates preservation of the cerebral function better than the recovery of electroencephalographic findings, and L-NAME was supposed to work neuroprotectively.

Permeability of the blood-brain barrier is activated during brain ischemia, and vasogenic brain edema occurs. It was reported that NO might take a role in this activation, ${ }^{20}$ and NOSI reduced brain edema of rats subjected to ischemia. ${ }^{21}$ From our experimental results the protective effect of NOSI against brain edema could not be detected because no significant difference was found between the control and treatment groups regarding cerebral tissue water content.

Extrapolation of animal data to humans must always be applied with extreme caution; however, the results of this study suggest that even if a prolonged circulatory arrest happens, treatment for reperfusion injury may salvage brain damage.

\section{Conclusion}

NO levels within the brain increased not during ischemia but during reperfusion under hypothermic circulatory arrest with CPB. NOSI (L-NAME) administered at the onset of reperfusion inhibited NO production and showed protective effects on the brain in terms of recovery of SEP. Under hypothermic circulatory arrest, NO might be one of the factors causing reperfusion injury after brain ischemia.

We thank Professor Takashi Yamada, PhD, of National Defense Medical College for statistical analysis.

REFERENCES

1. Malinski T, Bailey F, Zhang ZG, Chopp M. Nitric oxide measured by a porphyrinic microsensor in rat brain after transient middle cerebral artery occlusion. J Cereb Blood Flow Metab 1993;13:355-8.

2. Ichimori K, Ishida H, Fukahori M, Nakazawa H, Murakami E. Practical nitric oxide measurement employing a nitric oxide-selective electrode. Rev Sci Instr 1994;65:1-5.

3. Huckabee WE. Relationship of pyruvate and lactate during anaerobic metabolism. V: Coronary adequacy. Am J Physiol 1961;200:1169-76. 
4. Kumura E, Kosaka H, Shiga T, Yoshimine T, Hayakawa T. Elevation of plasma nitric oxide end products during focal cerebral ischemia and reperfusion in the rat. J Cereb Blood Flow Metab 1994;14:487-91.

5. Iadeola C, Pelligrino DA, Moskowitz MA, Lassen NA. Nitric oxide synthase inhibition and cerebrovascular regulation. J Cereb Blood Flow Metab 1994;114:175-92.

6. Nowicki JP, Duval D, Poignet H, Scatton B. Nitric oxide mediate neuronal death after focal cerebral ischemia in the mouse. Eur J Pharmacol 1991;204:339-40.

7. Buisson A, Plotkine M, Boulu RG. The neuroprotective effect of a nitric oxide inhibitor in a rat model of focal cerebral ischemia. Br J Pharmacol 1992;106:766-7.

8. Ashwal S, Cole DJ, Osborne TN, Pearce WJ. Low dose L-NAME reduces infarct volume in the rat MCAO/reperfusion model. J Neurosurg Anesth 1993;5:241-9.

9. Morikawa E, Huang A, Moskowitz MA. l-Arginine decreases infarct size caused by middle cerebral artery occlusion in SHR. Am J Physiol 1992;263:H1632-5.

10. Dawson DA, Kusumoto K, Graham DI, McCulloch J, Macrae IM: Inhibition of nitric oxide synthesis does not reduce infarct volume in a rat model of focal cerebral ischemia. Neurosci Lett 1992;142:151-4.

11. Tsui SSL, Kirshbom PM, Davies MJ, Jacobs MT, Greeley WJ, Kern FH, et al. Nitric oxide production affects cerebral perfusion and metabolism after deep hypothermic circulatory arrest. Ann Thorac Surg 1996;61:1699-1707.

12. Hiramatsu T, Jonas RA, Miura T, duPlessis A, Tanji M, Forbess JM, et al. Cerebral metabolic recovery from deep hypothermic circulatory arrest after treatment with arginine and nitro-arginine methyl ester. J Thorac Cardiovasc Surg 1996;112:698-707.
13. Anderson RE, Meyer FB. Nitric oxide synthase inhibition by L-NAME during repetitive focal cerebral ischemia in rabbits. Am J Physiol 1996;271:H588-94.

14. Ferriero DM, Sheldon RA, Black SM, Chuai J. Selective destruction of nitric oxide synthase neurons with quisqualate reduces damage after hypoxia-ischemia in the neonatal rat. Pediatric Res 1995;38:912-8.

15. Lipton SA, Choi YB, Pan ZH, Lei SZ, Chen HSV, Sucher $\mathrm{NJ}$, et al. A redox-based mechanism for the neuroprotective and neurodestructive effects of nitric oxide and related nitroso-compounds. Nature 1993;364:626-32.

16. van der Vliet A, Eiserich JP, O’Neil CA, Halliwell B, Cross CE. Tyrosine modification by reactive nitrogen species: a closer look. Arch Biochem Biophys 1995;31:341-9.

17. Yoshida T, Limmroth V, Irikura K, Moskowitz MA. The NOS inhibitor, 7-nitroindazole, decreases focal infarct volume but not the response to topical acetylcholine in pial vessels. J Cereb Blood Flow Metab 1994;14:924-9.

18. Huang Z, Huang P, Panahian N, Dalkara T, Fishman MC, Moskowitz MA. Effects of cerebral ischemia in mice deficient in neuronal nitric oxide synthase. Science 1994;265:1883-5.

19. Kurose I, Wolf R, Grisham MB, Granger DN. Effects of endogenous inhibitor of nitric oxide synthesis on post capillary venules. Am J Physiol 1995;1268:H2224-31.

20. Sancesario G, Iannone M, Morello M, Nistico G, Bernardi G. Nitric oxide inhibition aggravates ischemic damage of hippocampal but not of NADPH neurons in gerbils. Stroke 1994;25:436-44.

21. Nagafuji T, Matsui T, Koide T, Asano T. Blockade of nitric oxide formation by NG-nitro-l-arginine mitigates ischemic brain edema and subsequent cerebral infarction in rats. Neurosci Lett 1991;147:159-62. 